Provided for non-commercial research and education use. Not for reproduction, distribution or commercial use.

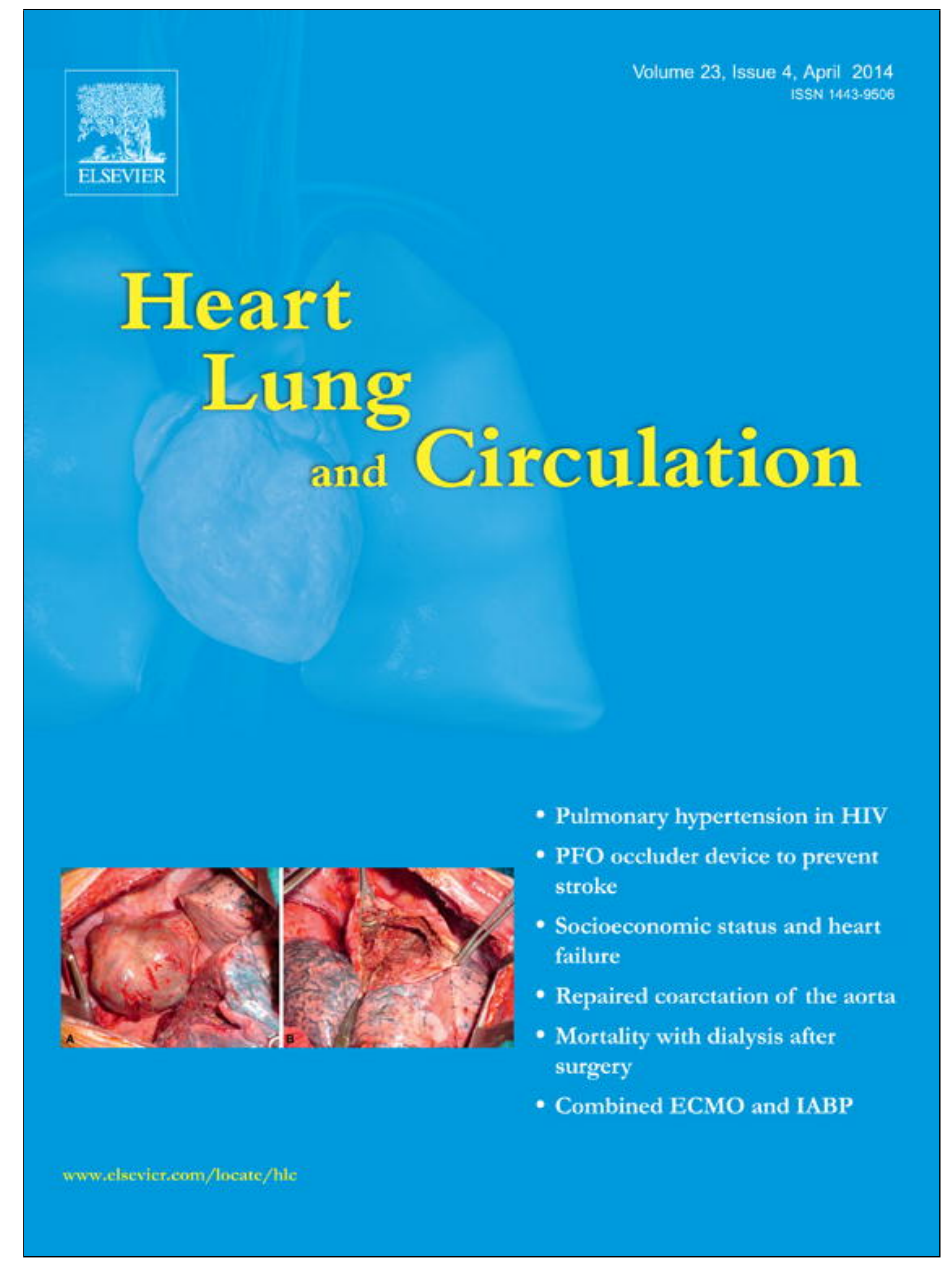

This article appeared in a journal published by Elsevier. The attached copy is furnished to the author for internal non-commercial research and education use, including for instruction at the authors institution and sharing with colleagues.

Other uses, including reproduction and distribution, or selling or licensing copies, or posting to personal, institutional or third party websites are prohibited.

In most cases authors are permitted to post their version of the article (e.g. in Word or Tex form) to their personal website or institutional repository. Authors requiring further information regarding Elsevier's archiving and manuscript policies are encouraged to visit:

http://www.elsevier.com/authorsrights 


\title{
The Impact of Beta-blockade on Right Ventricular Function in Mitral Regurgitation
}

\author{
Yin Hongning ${ }^{a}$, Ralph A. Stewart ${ }^{b}$, Gillian A. Whalley ${ }^{c^{*}}$ \\ ${ }^{a}$ The 2nd Hospital of Hebei Medical University, Shijiazhuang, China \\ ${ }^{\mathrm{b}}$ Auckland City Hospital, Auckland, New Zealand \\ ${ }^{c}$ Unitec, Auckland, New Zealand \\ Received 8 April 2013; received in revised form 11 October 2013; accepted 22 October 2013; online published-ahead-of-print 1 November 2013
}

Background Although mitral regurgitation (MR) results in left ventricular (LV) volume overload, right ventricular (RV) function may also be impaired. We investigated the influence of short-term beta-blockade on RV function in patients with moderate-severe MR.

Methods Twenty-six patients were randomised in a cross-over design to receive two weeks of beta-blockade or placebo. Echocardiography was performed at baseline and at the end of the treatment periods. Measurements included: RV ejection fraction (RVEF) tricuspid annular motion and Tei index.

Results $\quad$ No differences in mean RVEF $(64.0 \pm 6.0 \mathrm{v} 67.0 \pm 8.0 \%, p=0.3)$, tricuspid annular motion $(13.5 \pm 3.0 \mathrm{v} 14.7$ $\pm 2.9 \mathrm{~cm} / \mathrm{s}, p=0.5)$, or median Tei index $(0.61(0.54,0.88) \mathrm{v} 0.59(0.54,0.74), p=0.8)$ were observed between placebo and metoprolol, despite significantly longer cardiac time intervals. Tei index under both conditions was significantly reduced.

Conclusions Short-term treatment with a beta-blocker did not influence RV function in these patients. Interestingly, the RV Tei index was high suggesting significant RV dysfunction despite normal RVEF.

Keywords Mitral regurgitation • Beta-blockers • Tei index • Echocardiography • Doppler

\section{Introduction}

Degenerative mitral regurgitation (MR) results in left ventricular (LV) volume overload and LV dysfunction that contributes to prognosis [1]. RV function is also prognostically important [2]: tricuspid annular plane systolic excursion (TAPSE), a measure of systolic annular descent, is correlated with RV ejection fraction (RVEF) [3] and predicts survival after mitral valve repair [4].

In patients with LV systolic dysfunction, beta-blockade improves prognosis [5] and reverses adverse LV remodelling [6], potentially mediated through a long-term reduction in myocyte strain, also seen with MR-related chronic LV volume overload [7]. Recently, we reported that short-term beta-blocker treatment did not change MR volume but decreased LV work in patients with moderate-severe MR [8]. The aim of this study was to investigate the influence of short-term beta-blocker on RV.

\section{Patients and Methods}

The methods have been reported elsewhere [8]. Briefly, patients with moderate-severe MR, normal LV systolic function (echo LV ejection fraction $>55 \%$ ) and sinus rhythm were recruited into this double-blind, randomised, crossover

*Corresponding author at: Unitec, Private Bag 92025, Auckland, New Zealand. Tel.: +64 21306509., Email: gwhalley@unitec.ac.nz

(C) 2013 Australian and New Zealand Society of Cardiac and Thoracic Surgeons (ANZSCTS) and the Cardiac Society of Australia and New Zealand (CSANZ). Published by Elsevier Inc. All rights reserved. 
design trial which had two treatment periods (14 \pm 3 days) with a two to four days washout between treatments. Subjects were randomised to extended-release metoprolol or placebo or vice versa. The initial dose was one continuousrelease metoprolol tablet $(47.5 \mathrm{mg})$ or placebo per day. The dose was increased every three to four days if the patient had no side effects, resting heart rate was $\geqq 60 \mathrm{bpm}$, and systolic blood pressure was $\geqq 110 \mathrm{~mm} \mathrm{Hg}$, with a maximum dose of $190 \mathrm{mg} / \mathrm{d}$. The dose was reduced if clinically indicated. All other medication was unchanged throughout. At baseline, and the end of each study period, clinical examination, ECG, and echocardiography were completed. Echocardiographic measurements were performed blind: RVEF (area-length method, apical four-chamber view); 2D TAPSE; pulsed-wave tissue Doppler imaging (TDI) of longitudinal RV free wall annular motion (systolic (Sm), early diastolic (Em), late diastolic (Am) velocities); Tei index (Tei index = (isovolumetric contraction time + isovolumic relaxation time)/ejection time). Similar measurements were obtained from the LV by both conventional and tissue Doppler (septal and lateral walls) methods. From the TDI recordings, the time interval from the end of one to the onset of the next tricuspid annular velocity pattern during diastole (a) was measured. The duration of the Sm (b) was measured from the onset to the end of the $\mathrm{Sm}$. The Tei index was calculated as $(a-b) / b$. Very few patients had sufficient tricuspid regurgitation to allow measurement of RV systolic pressure.

\section{Statistical Analysis}

Continuous variables were compared by treatment arm using paired Student $t$-tests (Wilcoxon for non-parametric data). Pearson correlation coefficients are reported, with a value of $p<0.05$ was considered statistically significant.

\section{Results}

Twenty-six patients were enrolled: mean age $61 \pm 10$ years; seven patients had mild dyspnoea on exertion (NYHA class IIa); 12 reported a history of treated hypertension. Most patients had posterior mitral leaflet prolapse (Table 1). Heart rate was significantly lower on metoprolol (65 $\pm 10 \mathrm{bpm}$ ) compared to placebo $(55 \pm 7 \mathrm{bpm})$, but no significant changes in RV volumes or function were observed (Table 2). Tei index was similar on metroprolol and placebo, despite there being a significantly longer $a$ time $(519 \mathrm{v} 476, p=0.005)$ and a trend towards longer $b$ time (309 v 299, $p=0.07$ ). Similar results were observed for LV Tei index (Table 2). Tei index under both conditions was significantly different to the published normal values for RV Tei index $(0.28 \pm 0.04$ by conventional Doppler [9] and $0.43 \pm 0.07$ [10]. We have previously reported no impact on LV volumes and $\mathrm{EF}$ [8] but this study confirmed similar stable results for LV parameters and also elevated LV Tei index (Table 2). The LV Tei index values are significantly different to the published normal values $(0.33 \pm 0.09$ by conventional Doppler and $0.42 \pm 0.09$ by TDI [11]).
Table 1 Demographic and Clinical Characteristics of the Study Population.

\begin{tabular}{|c|c|}
\hline Characteristic & $\begin{array}{l}\text { Whole group } \\
\qquad(N=26)\end{array}$ \\
\hline Age, years & $61 \pm 10$ \\
\hline Male, $n(\%)$ & $21(84)$ \\
\hline \multicolumn{2}{|l|}{ Ethnic group, $n(\%)$} \\
\hline White & $20(80)$ \\
\hline Maori/Pacific Islander & $3(12)$ \\
\hline Other & $2(8)$ \\
\hline Body mass index, $\mathrm{kg} / \mathrm{m}^{2}$ & $25.8 \pm 3.8$ \\
\hline History of hypertension, $n(\%)$ & $12(48)$ \\
\hline \multicolumn{2}{|l|}{ Medical treatment during study } \\
\hline ACE inhibitor, $n(\%)$ & $11(44)$ \\
\hline Loop diuretic, $n(\%)$ & $1(4)$ \\
\hline \multicolumn{2}{|l|}{ Symptoms } \\
\hline Asymptomatic, $n(\%)$ & $19(73)$ \\
\hline NYHA class a symptoms, $n(\%)$ & $7(28)$ \\
\hline \multicolumn{2}{|l|}{ Leaflet prolapse } \\
\hline Anterior leaflet, $n(\%)$ & $2(8)$ \\
\hline Posterior leaflet, $n(\%)$ & $14(56)$ \\
\hline Bileaflet, $n(\%)$ & $9(36)$ \\
\hline Flail or partial flail mitral leaflet, $n(\%)$ & $11(44)$ \\
\hline \multicolumn{2}{|l|}{ Echocardiography } \\
\hline LV end-systolic volume, mL & $81 \pm 21$ \\
\hline LV end-diastolic volume, $\mathrm{mL}$ & $229 \pm 50$ \\
\hline LV ejection fraction, $\%$ & $65 \pm 5$ \\
\hline Mitral regurgitant volume, $\mathrm{mL}$ & $59 \pm 36$ \\
\hline
\end{tabular}

Data are mean \pm SD or number (percentage).

Abbreviations: ACE, angiotensin-converting enzyme; NYHA, New York Heart Association.

\section{Discussion}

We have demonstrated that RV function in patients with MR is not influenced by short-term beta-blocker treatment. However, the RV Tei indices were substantially higher than reported normal values [9], suggesting significant RV dysfunction despite normal RVEF. Thus, the Tei index, a measure of global cardiac function [9], might be a more sensitive parameter to estimate the RV dysfunction. Similar results were observed for the LV Tei index.

This was a small study, possibly underpowered that is mostly hypothesis generating. We have used some published normal values for RV Tei and it is acknowledged that including our own control group would have been optimal. Future work should validate the Tei index measured from Tissue Doppler in this setting against a control series, should include more complex assessment of systolic time intervals, and ideally should include 3D echo and global longitudinal strain.

Early detection of ventricular dysfunction is crucial in the setting of severe MR: by the time LV dysfunction is apparent using conventional echocardiography it is often irreversible. 
Table 2 Effects of Metoprolol on Heart Rate and Ventricular Function.

\begin{tabular}{|c|c|c|c|}
\hline & Placebo $(N=26)$ & Metoprolol $(N=26)$ & $p$ value \\
\hline Heart rate, bpm & $65 \pm 10$ & $55 \pm 7$ & $<0.0001$ \\
\hline RV end-systolic volume, mL & $19.1 \pm 7.5$ & $18.3 \pm 8.3$ & 0.7 \\
\hline $\mathrm{RV}$ end-diastolic volume, $\mathrm{mL}$ & $52.9 \pm 18.9$ & $55.8 \pm 18.1$ & 0.5 \\
\hline RV ejection fraction, $\%$ & $64.0 \pm 6.0$ & $67.0 \pm 8.0$ & 0.3 \\
\hline RV TAPSE, cm & $2.57 \pm 0.34$ & $2.63 \pm 0.40$ & 0.9 \\
\hline Tricuspid systolic annular velocity, $\mathrm{cm} / \mathrm{s}$ & $13.5 \pm 3.0$ & $14.7 \pm 2.9$ & 0.5 \\
\hline TDI RV Em/Am & $0.87(0.75-1.43)$ & $0.81(0.65-1.13)$ & 0.97 \\
\hline TDI RV time $a, \mathrm{~ms}$ & $476(443-493)$ & $519(492-535)$ & 0.005 \\
\hline TDI RV time $b, \mathrm{~ms}$ & $299(262-312)$ & $309(293-339)$ & 0.07 \\
\hline TDI RV Tei index & $0.61(0.54-0.88)$ & $0.59(0.54-0.74)$ & 0.8 \\
\hline \multicolumn{4}{|l|}{ Left ventricular Tei measurements } \\
\hline Mitral LV time $a$, ms & $432.7 \pm 48.0$ & $455.8 \pm 53.5$ & 0.003 \\
\hline Mitral LV time $b$, ms & $261.6 \pm 32.5$ & $271.6 \pm 36.2$ & 0.009 \\
\hline Mitral LV Tei index & $0.68(0.58-0.81)$ & $0.61(0.52-0.80)$ & 0.59 \\
\hline TDI (lateral) LV time $a$, ms & $446.3 \pm 60.7$ & $506.4 \pm 50.6$ & 0.005 \\
\hline TDI (lateral) LV time $b, \mathrm{~ms}$ & $275.5 \pm 46.8$ & $299.3 \pm 39.9$ & 0.003 \\
\hline TDI (lateral) LV Tei index & $0.64(0.57-0.84)$ & $0.67(0.57-0.78)$ & 0.97 \\
\hline TDI (septal) LV time $a$, ms & $477.8 \pm 54.3$ & $494.8 \pm 52.5$ & 0.115 \\
\hline TDI (septal) LV time $b, \mathrm{~ms}$ & $295.9 \pm 34.6$ & $314.5 \pm 34.7$ & 0.007 \\
\hline TDI (septal) LV Tei index & $0.62(0.57-0.69)$ & $0.56(0.50-0.67)$ & 0.19 \\
\hline
\end{tabular}

Abbreviations: $a$, the time interval from the end of one to the onset of the next tricuspid annular velocity pattern during diastole; $b$, duration of systole using systolic annular velocity; Am, late mitral annular velocity; Em, early mitral annular velocity; LV, left ventricle; $R V$, right ventricle; TAPSE, tricuspid annular plane systolic excursion; Data are mean \pm standard deviation or median (95\% confidence interval).

However, if more objective measures of both RV and LV systolic dysfunction were available, perhaps a more precise management might be obtainable.

\section{References}

[1] Ross J. Left ventricular function and the timing of surgical treatment in valvular heart disease. Ann Intern Med 1981;94:498-504

[2] Borer JS, Hochreiter C, Rosen S. Right ventricular function in severe non-ischaemic mitral insufficiency. Eur Heart J 1991;12(Suppl. B):22-5.

[3] Kaul S, Tei C, Hopkins JM, Shah PM. Assessment of right ventricular function using two-dimensional echocardiography. Am Heart J 1984;107: 526-31.

[4] Di Mauro M, Calafiore AM, Penco M, Romano S, Di Giammarco G, Gallina S. Mitral valve repair for dilated cardiomyopathy: predictive role of right ventricular dysfunction. Eur Heart J 2007;28:2510-6.

[5] The Cardiac Insufficiency Bisoprolol Study II (CIBIS-II): a randomized trial. Lancet 1999;353:9-13.

[6] Doughty RN, Whalley GA, Gamble G, MacMahon S, Sharpe N. Left ventricular remodeling with carvedilol in patients with congestive heart failure due to ischemic heart disease: Australia-New Zealand Heart Failure Research Collaborative Group. J Am Coll Cardiol 1997;29: 1060-6.

[7] Opie LH, Commerford PJ, Gersh BJ, Pfeffer MA. Controversies in ventricular remodeling. Lancet 2006;367:356-67.

[8] Ralph S, Owen R, Andrew K, Ruvin G, Irene M, Alistair Y, et al. Pilot study to assess the influence of beta-blockade on mitral regurgitant volume and left ventricular work in degenerative mitral valve disease. Circulation 2008;118:1041-6.

[9] Tei C, Dujardin KS, Hodge DO, Bailey KR, McGoon MD, Tajik AJ, et al. Doppler echocardiographic index for assessment of global right ventricular function. J Am Soc Echocardiogr 1996;9:838-47.

[10] Özdemir K, Altunkeser BB, Gök H, çli A. Does the myocardial performance index affect pulmonary artery pressure in patients with mitral stenosis? A tissue doppler imaging study. Echocardiography 2003;20:249-56

[11] Gaibazzi N, Petrucci N, Ziacchi V. Left ventricle myocardial performance index derived either by conventional method or mitral annulus tissue-doppler: a comparison study in healthy subjects and subjects with heart failure. J Am Soc Echocardiogr 2005;18:1270-6. 